$5 \quad$ Ito $^{1^{*}}$

6

\section{Abstract}

\section{protein}

\title{
Taurine suppresses liquid-liquid phase separation of lysozyme
}

Kanae Tsubotani ${ }^{1}$, Sayuri Maeyama ${ }^{1}$, Shigeru Murakami1 ${ }^{1}$, Stephen W Schaffer ${ }^{2}$, Takashi

1: Department of Biosciences and Biotechnology, Fukui Prefectural University.

4-1-1 Matsuokakenjojima, Eiheiji-cho, Yoshida-gun, Fukui 910-1195, Japan

2: College of Medicine, University of South Alabama.

5795 USA Drive North, CSAB 170, Mobile, AL 36688, USA

*: Corresponding author. tito@fpu.ac.jp

Taurine is a compatible osmolyte that infers stability to proteins. Recent studies have revealed that liquid-liquid phase separation (LLPS) of proteins underlie the formation of membraneless organelles in cells. In the present study, we evaluated the role of taurine on LLPS of hen egg lysozyme. We demonstrated that taurine decreases the turbidity of the polyethylene glycol-induced crowding solution of lysozyme. We also demonstrated that taurine attenuates LLPS-dependent cloudiness of lysozyme solution with 0.5 or $1 \mathrm{M} \mathrm{NaCl}$ at a critical temperature. Moreover, we observed that taurine inhibits LLPS formation of a heteroprotein mix solution of lysozyme and ovalbumin. These data indicate that taurine can modulate the formation of LLPS of proteins. 
bioRxiv preprint doi: https://doi.org/10.1101/2021.01.26.428332; this version posted January 27, 2021. The copyright holder for this preprint (which was not certified by peer review) is the author/funder, who has granted bioRxiv a license to display the preprint in perpetuity. It is made available under aCC-BY-NC-ND 4.0 International license.

25 Keywords

26 taurine, protein stability, liquid-liquid phase separation, lysozyme

27

28

29 


\section{Introduction}

Recent studies have demonstrated that liquid-liquid phase separation (LLPS) of proteins and nucleic acids is associated with the assembly of membraneless organelle in cells. It plays a critical role in a variety of normal cellular activities; i.e. the formation of stress granules, nucleoli, and the condensation of proteins related to glucose metabolism and cell signaling (Banani et al. 2017; Kohnhorst et al. 2017; Zhang et al. 2020; Kamagata et al. 2020). Moreover, aberrant LLPS of many proteins, such as FUS, TDP-43, tau, and \#alpha-synuclein, leads to fibril formation, which is related to neurodegenerative diseases (Zhang et al. 2017; Murray et al. 2017; Choi et al. 2018; Ray et al. 2020).

LLPS formation of proteins occurs through electrostatic interactions between amino acid residues, such as dipole-dipole, cation- $\pi$, \#p-\#p interactions (Nott et al. 2015; Vernon et al. 2018; Hofweber et al. 2018; Qamar et al. 2018). In many cases, LLPS formation requires a high protein concentration and changes in medium salt concentration, $\mathrm{pH}$, temperature, pressure, etc (Zaslavsky et al. 2018; Cinar et al. 2019; Singh et al. 2020). In other cases, posttranslational modifications, such as phosphorylation and methylation, influence LLPS formation (Wippich et al. 2013; Wegmann et al. 2018; Ferreon et al. 2018; Milovanovic et al. 2018). Importantly, intrinsic small molecules also influence LLPS formation (Shiraki et al. 2020). For example, Patal et al. have demonstrated that ATP works as a hydrotrope, thereby inhibiting LLPS formation of proteins (Patel et al. 2017). This discovery raises the possibility of a novel role of cellular metabolites as regulators of LLPS formation.

Taurine is a beta-amino acid found in high concentration (typically $1 \sim 40 \mathrm{mmol} / \mathrm{kg}$ tissue weight) in mammalian tissues (Chesney 1985; Ito et al. 2008; Jentsch 2016) v. Taurine functions as a compatible organic osmolyte, which regulates intracellular ionic balance, 
thereby maintaining cell volume (Schaffer et al. 2000, 2010). Compatible osmolytes also contribute to the thermodynamic stability of proteins by minimizing the water-protein interaction (Bruździak et al. 2018). The role of compatible osmolytes in LLPS formation of proteins has been evaluated by Cinar et al., who demonstrated that trimethylamine oxide (TMAO), which is an organic osmolyte of marine fish, enhances LLPS formation of gamma-crystallin(Cinar et al. 2019). Abe et al. demonstrated that taurine can weakly interact with hen egg lysozyme protein, including cation-\#pai interaction, in crowding condition (Abe et al. 2015). Therefore, we hypothesized that taurine can regulate LLPS formation through its potential to interact with the protein surface, as well as directly with water.

Lysozyme is a frequently used model protein to study protein folding and aggregation. Lysozyme forms LLPS by adding a high concentration of salt or by mixing with ovalbumin (Taratuta et al. 1990; Muschol and Rosenberger 1997; Dumetz et al. 2008; Santos et al. 2018; Iwashita et al. 2018; Bye and Curtis 2019). Therefore, in the present study, we studied the effect of taurine on LLPS formation of lysozyme.

\section{Methods}

\section{Materials}

Hen egg lysozyme was kindly provided by QP Co. (Japan). Ovalbumin was obtained from Sigma-Aldrich (USA). Taurine and other chemicals were purchased from Nacalai Tesque (Japan). 
A standard Tris buffer [20 mM Tris- $\mathrm{HCl}(\mathrm{pH} 7.4)]$ was prepared. The $\mathrm{pH}$ of the Tris buffer was readjusted back to $\mathrm{pH} 7.4$ after adding taurine. Lysozyme powder was dissolved in water and then mixed with standard Tris buffer and 5M NaCl solution. The lysozyme solutions were incubated at the indicated temperature $\left(0 \sim 20^{\circ} \mathrm{C}\right)$ by a Cool-thermo unit (Titec Co., Japan). After a 5 min incubation at each temperature, the cloudiness (whiteness) of the lysozyme solution was confirmed visually.

\section{LLPS formation by mixing lysozyme and ovalbumin}

The formation of LLPS containing lysozyme and ovalbumin was performed according to previous reports (Santos et al. 2018; Iwashita et al. 2018), with a few modifications. In the first experiment, a lysozyme solution (\#mg/mL in water) and an ovalbumin solution (\#mg/mL in water) were mixed 1:1 ratio in water (final concentration is $2.5 \mathrm{mg} / \mathrm{mL}$ each). Taurine $(0,20$, or $200 \mathrm{mM})$ was added before mixing the proteins. 20 \#microL of the solution was applied to a disposal cell counter plate (Watson Co., Japan) and then LLPS formation was checked with optical microscopies (BZ-X800, Keyence, Japan). The turbidity of the solution was measured in 96 -well microplates by using a UV-Vis microplate reader (Spectramax M2 microplate reader, Molecular Devices, USA). microscopy (BZ-X800, Keyence). 


\section{Taurine inhibits the opalescence of lysozyme in supersaturated state.}

101 The crowding condition by adding polyethylene glycol (PEG) is a common method to 102 observe LLPS of various proteins (Kaur et al. 2019). We tried to detect LLPS formation of 103 lysozyme after crowding following addition of PEG-6000. Although the solution was 104 cloudy, liquid droplet formation was not confirmed, as assessed by optical microscopy 105 (Figure 1).

106 We tested the effect of the cloudiness of the PEG-containing lysozyme solution. While 107 increasing PEG concentration up to $20 \%$ increased the absorbance of the lysozyme solution 108 (50 mg/mL) in Tris buffer (pH7.4) at room temperature, the absorbance was sharply 109 increased at $25 \%$ PEG. The sharp increase in turbidity may be due to the precipitation of 110 protein (Kaur et al. 2019). The addition of $100 \mathrm{mM}$ taurine decreased the turbidity of the 111 lysozyme solution $(50 \mathrm{mg} / \mathrm{mL})$. Figure $1 \mathrm{~B}, \mathrm{C}$ shows the turbidity data of PEG-containing 112 lysozyme solution.

\section{Taurine inhibits LLPS of lysozyme in the presence of a high $\mathrm{NaCl}$ concentration.}

Lysozyme forms LLPS in the presence of high $\mathrm{NaCl}$ and below a critical temperature 116 (Muschol and Rosenberger 1997). To determine whether taurine can modulate LLPS 117 formation, we tested the influence of taurine on the temperature at which LLPS started to 118 form. Figure 2 shows the clouding point for lysozyme at two different $\mathrm{NaCl}$ concentrations,

$0.5 \mathrm{M}$, and $1 \mathrm{M}$, in the presence or absence of taurine $(0,20,200 \mathrm{mM})$. The addition of taurine decreased the clouding point temperature for $100 \mathrm{mg} / \mathrm{mL}$ lysozyme in the presence

121 of $0.5 \mathrm{M} \mathrm{NaCl}$; while the lysozyme solution without taurine started to become cloudy at $9{ }^{\circ} \mathrm{C}$, 122 the solution with $200 \mathrm{mM}$ taurine started to become cloudy at $6{ }^{\circ} \mathrm{C}$ while 20 and $50 \mathrm{mM}$ 123 taurine shifted the clouding point to $8^{\circ} \mathrm{C}$. In $1 \mathrm{M} \mathrm{NaCl}$ solution, the addition of $200 \mathrm{mM}$ 
124 taurine, but not 20 or $50 \mathrm{mM}$, also decreased in the clouding point temperature; taurine

125 shifted it from $26^{\circ} \mathrm{C}$ to $24{ }^{\circ} \mathrm{C}$ in $100 \mathrm{mg}$ lysozyme solution.

\section{Taurine inhibits LLPS formation of heteroprotein mix, lysozyme and ovalbumin.}

Lysozyme forms LLPS by mixing with ovalbumin (Santos et al. 2018; Iwashita et al.

2018). Next, we tested the influence of taurine on heteroprotein LLPS formation of

lysozyme and ovalbumin. LLPS formation was monitored by phase-contrast microscopy.

131 Two proteins were mixed at a 1:1 ratio $(1 \mathrm{mg} / \mathrm{mL}$ each) in a Tris-buffered solution $(5 \mathrm{mM}$,

$132 \mathrm{pH7.4}$, Figure 3A). Mixing two proteins generates droplets. The addition of 20 100 mM

133 taurine decreased the size of droplets of the heteroprotein mix (Figure 3B). The addition of

$134200 \mathrm{mM}$ taurine prevented LLPS formation.

135 Furthermore, we confirmed LLPS formation of lysozyme and ovalbumin by using

136 FITC-labelled lysozyme instead of non-labeled lysozyme to reveal whether lysozyme itself

137 is contained in liquid droplets. As shown in Figure 4, liquid droplets were observed by

138 fluorescent microscopy, indicating that FITC-labelled lysozyme forms LLPS. No

139 fluorescent droplets were confirmed in heteroprotein mix solution without FITC-labeled

140 lysozyme. Moreover, the addition of taurine decreased the number and size of liquid 141 droplets.

Since the previous reports used water as a reaction buffer instead of Tris buffer to

143 form LLPS of lysozyme and ovalbumin, we also tested LLPS formation of two proteins in 144 water (Figure S1). The addition of taurine did not largely change the $\mathrm{pH}$ of the 145 heteroprotein solution. Increasing turbidity was observed in this condition, and the 146 addition of taurine decreased turbidity. The droplet was confirmed by light microscopy. 147 The addition of $200 \mathrm{mM}$ taurine, but not $20 \mathrm{mM}$, inhibits LLPS formation. 


\section{Discussion} in solution. The surface of stable proteins contain positively and negatively charged amino acid side chains. Ionic interactions readily develop between these charged amino acid side chains and either salts or other charged compounds, including taurine. According to Abe et al taurine supports the folding of lysozyme under a crowding condition (Abe et al. 2015). Their NMR analysis revealed an interaction between taurine and hydrophilic residues. However, a cation-pi interaction of taurine with tryptophan residues has been reported. Meanwhile, beta-alanine, which is a similar chemical structure to taurine and has carboxylic acid instead of sulfonic acid, does not interact with lysozyme, indicating the specific action of taurine against lysozyme. Additionally, they also identified the interaction between taurine and the disordered regions of CedA protein and PriC

N-terminal domain. Bruzdziak et al. demonstrated that the amino-group of taurine interacts with the side chain of lysozyme as assessed by thermodynamic analysis (Bruździak et al. 2018). Given the importance of the cation-\#pai interaction and the disordered regions of proteins for LLPS formation, the weak interaction between taurine and proteins may contribute to the inhibition of LLPS formation. 
anions and cations that are water structure breakers have also been found to stabilize

172 protein structure. Central to the action of the water structure breakers is the effect of nonpolar residues on water structuring. In the stable protein, nonpolar residues, such as isoleucine, are buried within the interior of the protein, which shields them from water. By contrast, in the denatured protein the nonpolar residues are exposed to aqueous medium. The exposed environment is thermodynamically unfavorable (entropy driven), as water forms large clusters around the nonpolar chains. Indeed, the most thermodynamically stable condition is one in which the nonpolar residues of proteins adhere to one another in the interior of the protein, so as to minimize water exposure, a condition called hydrophobic bonding. Some compounds compete with hydrophobic groups for available water molecules,

Bruździak et al. 2018). The contribution of hydrophobic bonding has been demonstrated regeneration. The effect of taurine on water structure and hydrophobic interactions may also contribute to inhibition of LLPS formation, since protein-water interaction may be a driving force of LLPS formation (Ribeiro et al. 2019). effect of LLPS formers; the addition of TMAO to a solution containing \#gamma-crystallin and TDP-43 protein enhances LLPS (Choi et al. 2018; Cinar et al. 2019). We also observed that TMAO increases LLPS formation of a heteroprotein mixture of lysozyme and 193 ovalbumin (Figure S2). Therefore, the influence of osmolytes differ depending on each 194 chemical. 
Taurine functions as the cytoprotective metabolite through various mechanisms, such as antioxidation, $\mathrm{Ca}^{2+}$ handling control, and energy metabolism, etc. (Schaffer et al. 2010). Taurine also has diverse pharmacological properties in diseases, including heart failure, liver diseases, diabetes, and neurodegenerative disease (Ito et al. 2012, 2014; Menzie et al. 2014; Miyazaki and Matsuzaki 2014). The findings of the present study suggest that the action of taurine against LLPS formation may relate to its cytoprotective and pharmacological roles. For example, taurine has been reported to ameliorate neurodegenerative diseases in mice, such as Alzheimer's disease model and Parkinson's disease model (Kim et al. 2014; Che et al. 2018). Therefore, the inhibitory effect of taurine on fibril formation of amylogenic proteins, amyloid-\#beta, and \#alpha-synuclein may be associated with the prevention of LLPS formation. As another example, taurine prevents

the hyperosmotic stress-induced formation of stress granules (Bounedjah et al. 2012).

208 Taurine might directly interact with stress granule-related proteins to prevent assembly. by an increase in cellular taurine concentration, which may lead to the dissolution of stress granules. Further studies are necessary to reveal the intracellular role of taurine against LLPS and taurine-related cellular functions.

\section{Acknowledgments}

215 Hen egg lysozyme was kindly gifted from QP Corporation (Japan). This study was 216 granted by Lotte Foundation (to Takashi Ito) and \#a competitive grant from Fukui 217 Prefecture University (to Takashi Ito). 


\section{References}

Abe Y, Ohkuri T, Yoshitomi S, et al (2015) Role of the osmolyte taurine on the folding of a model protein, hen egg white lysozyme, under a crowding condition. Amino Acids 47:909-915. https://doi.org/10.1007/s00726-015-1918-0

Banani SF, Lee HO, Hyman AA, Rosen MK (2017) Biomolecular condensates: Organizers of cellular biochemistry. Nat. Rev. Mol. Cell Biol. 18:285-298

Bounedjah O, Hamon L, Savarin P, et al (2012) Macromolecular crowding regulates assembly of mRNA stress granules after osmotic stress: New role for compatible osmolytes. J Biol Chem 287:2446-2458. https://doi.org/10.1074/jbc.M111.292748

Bruździak P, Panuszko A, Kaczkowska E, et al (2018) Taurine as a water structure breaker and protein stabilizer. Amino Acids 50:125-140. https://doi.org/10.1007/s00726-017-2499-x

Bye JW, Curtis RA (2019) Controlling Phase Separation of Lysozyme with Polyvalent Anions. J Phys Chem B 123:593-605. https://doi.org/10.1021/acs.jpcb.8b10868

Che Y, Hou L, Sun F, et al (2018) Taurine protects dopaminergic neurons in a mouse Parkinson's disease model through inhibition of microglial M1 polarization. Cell Death Dis 9:. https://doi.org/10.1038/s41419-018-0468-2

Chesney RW (1985) Taurine: its biological role and clinical implications. Adv. Pediatr. $32: 1-42$

Choi KJ, Tsoi PS, Moosa MM, et al (2018) A Chemical Chaperone Decouples TDP-43 Disordered Domain Phase Separation from Fibrillation. Biochemistry 57:6822-6826. https://doi.org/10.1021/acs.biochem.8b01051

Cinar S, Cinar H, Chan HS, Winter R (2019) Pressure-Sensitive and Osmolyte-Modulated Liquid-Liquid Phase Separation of Eye-Lens Y-Crystallins. J Am Chem Soc 
Dumetz AC, Chockla AM, Kaler EW, Lenhoff AM (2008) Protein phase behavior in aqueous solutions: Crystallization, liquid-liquid phase separation, gels, and aggregates.

Ferreon JC, Jain A, Choi KJ, et al (2018) Acetylation disfavors tau phase separation. Int J

Hofweber M, Hutten S, Bourgeois B, et al (2018) Phase Separation of FUS Is Suppressed by Its Nuclear Import Receptor and Arginine Methylation. Cell 173:706-719.e13.

Ito T, Kimura Y, Uozumi Y, et al (2008) Taurine depletion caused by knocking out the https://doi.org/10.1016/j.cell.2018.03.004 taurine transporter gene leads to cardiomyopathy with cardiac atrophy. J Mol Cell Cardiol 44:927-937. https://doi.org/10.1016/j.yjmcc.2008.03.001

Ito T, Schaffer S, Azuma J (2014) The effect of taurine on chronic heart failure: Actions of taurine against catecholamine and angiotensin II. Amino Acids 46:111-119

Ito T, Schaffer SW, Azuma J (2012) The potential usefulness of taurine on diabetes mellitus and its complications. Amino Acids 42:1529-1539

Iwashita K, Handa A, Shiraki K (2018) Coacervates and coaggregates: Liquid-liquid and liquid-solid phase transitions by native and unfolded protein complexes. Int J Biol Macromol 120:10-18. https://doi.org/10.1016/j.ijbiomac.2018.08.063

Jentsch TJ (2016) VRACs and other ion channels and transporters in the regulation of cell volume and beyond. Nat. Rev. Mol. Cell Biol. 17:293-307

Kamagata K, Kanbayashi S, Honda M, et al (2020) Liquid-like droplet formation by tumor suppressor p53 induced by multivalent electrostatic interactions between two disordered domains. Sci Rep 10: https://doi.org/10.1038/s41598-020-57521-w 
267 Kaur T, Alshareedah I, Wang W, et al (2019) Molecular Crowding Tunes Material States of 268 Ribonucleoprotein Condensates. Biomolecules 9:71.

Kim HY, Kim H V., Yoon JH, et al (2014) Taurine in drinking water recovers learning and

Kohnhorst CL, Kyoung M, Jeon M, et al (2017) Identification of a multienzyme complex for

$$
\text { https://doi.org/10.1074/jbc.M117.783050 }
$$

Menzie J, Pan C, Prentice H, Wu JY (2014) Taurine and central nervous system disorders. Amino Acids 46:31-46

Milovanovic D, Wu Y, Bian X, De Camilli P (2018) A liquid phase of synapsin and lipid vesicles. Science (80- ) 361:604-607. https://doi.org/10.1126/science.aat5671

Miyazaki T, Matsuzaki Y (2014) Taurine and liver diseases: A focus on the heterogeneous protective properties of taurine. Amino Acids 46:101-110

Murray DT, Kato M, Lin Y, et al (2017) Structure of FUS Protein Fibrils and Its Relevance to Self-Assembly and Phase Separation of Low-Complexity Domains. Cell 171:615-627.e16. https://doi.org/10.1016/j.cell.2017.08.048

Muschol M, Rosenberger F (1997) Liquid-liquid phase separation in supersaturated lysozyme solutions and associated precipitate formation/crystallization. J Chem Phys 107:1953-1962. https://doi.org/10.1063/1.474547

Nott TJ, Petsalaki E, Farber P, et al (2015) Phase Transition of a Disordered Nuage Protein Generates Environmentally Responsive Membraneless Organelles. Mol Cell 57:936-947. https://doi.org/10.1016/j.molcel.2015.01.013 
291 Patel A, Malinovska L, Saha S, et al (2017) Biochemistry: ATP as a biological hydrotrope.

292 Science (80- ) 356:753-756. https://doi.org/10.1126/science.aaf6846

Qamar S, Wang GZ, Randle SJ, et al (2018) FUS Phase Separation Is Modulated by a

Ray S, Singh N, Kumar R, et al (2020) a-Synuclein aggregation nucleates through liquid-liquid phase separation. Nat Chem 12:705-716.

https://doi.org/10.1038/s41557-020-0465-9

Ribeiro SS, Samanta N, Ebbinghaus S, Marcos JC (2019) The synergic effect of water and biomolecules in intracellular phase separation. Nat. Rev. Chem. 3:552-561

Santos MB, Costa AR da, Garcia-Rojas EE (2018) Heteroprotein complex coacervates of ovalbumin and lysozyme: Formation and thermodynamic characterization. Int J Biol Macromol 106:1323-1329. https://doi.org/10.1016/j.ijbiomac.2017.08.132

Schaffer S, Takahashi K, Azuma J (2000) Role of osmoregulation in the actions of taurine. In: Amino Acids. Springer Wien, pp 527-546

Schaffer SW, Ju Jong C, Kc R, Azuma J (2010) Physiological roles of taurine in heart and muscle. In: Journal of Biomedical Science. BioMed Central, p S2

Shiraki K, Mimura M, Nishinami S, Ura T (2020) Effect of additives on liquid droplets and aggregates of proteins. Biophys. Rev. 12:587-592

Singh V, Xu L, Boyko S, et al (2020) Zinc promotes liquid-liquid phase separation of tau protein. J Biol Chem 295:5850-5856. https://doi.org/10.1074/jbc.AC120.013166

Taratuta VG, Holschbach A, Thurston GM, et al (1990) Liquid-liquid phase separation of aqueous lysozyme solutions: Effects of $\mathrm{pH}$ and salt identity. J Phys Chem 94:2140-2144. https://doi.org/10.1021/j100368a074 
Vernon RMC, Chong PA, Tsang B, et al (2018) Pi-Pi contacts are an overlooked protein feature relevant to phase separation. Elife $7:$ https://doi.org/10.7554/eLife.31486

Wegmann S, Eftekharzadeh B, Tepper K, et al (2018) Tau protein liquid-liquid phase separation can initiate tau aggregation. EMBO J 37:

https://doi.org/10.15252/embj.201798049

Wippich F, Bodenmiller B, Trajkovska MG, et al (2013) Dual specificity kinase DYRK3 couples stress granule condensation/ dissolution to mTORC1 signaling. Cell 152:791-805. https://doi.org/10.1016/j.cell.2013.01.033

Yancey PH (2005) Organic osmolytes as compatible, metabolic and counteracting cytoprotectants in high osmolarity and other stresses. J. Exp. Biol. 208:2819-2830

Zaslavsky BY, Ferreira LA, Darling AL, Uversky VN (2018) The solvent side of proteinaceous membrane-less organelles in light of aqueous two-phase systems. Int. J. Biol. Macromol. 117:1224-1251

Zhang JZ, Lu TW, Stolerman LM, et al (2020) Phase Separation of a PKA Regulatory Subunit Controls cAMP Compartmentation and Oncogenic Signaling. Cell 182:1531-1544.e15. https://doi.org/10.1016/j.cell.2020.07.043

Zhang X, Lin Y, Eschmann NA, et al (2017) RNA stores tau reversibly in complex coacervates. PLOS Biol 15:e2002183. https://doi.org/10.1371/journal.pbio.2002183 


\section{Figures}

Figure 1 Absorbance $(\lambda=550 \mathrm{~nm})$ of PEG-containing lysozyme solution $(50 \mathrm{mg})$. Effect of 20 and $100 \mathrm{mM}$ taurine on PEG-induced turbidity of lysozyme was measured.

Figure 2 Effect of taurine on $\mathrm{NaCl}$ and temperature-dependent LLPS of lysozyme.(A,B) Cloud point data for lysozyme solution at $0.5 \mathrm{M}(\mathrm{A})$ or $1 \mathrm{M}(\mathrm{B}) \mathrm{NaCl}$ concentration with or without taurine. Lower picutres: epresentative clouded lysozyme solution in $0.5 \mathrm{M} \mathrm{NaCl}$ at $9^{\circ} \mathrm{C}$ and in $1 \mathrm{M}$ at $26^{\circ} \mathrm{C}$.

Figure 3 Effect of taurine on LLPS of lysozyme and ovalbumin mix solution $(2.5 \mathrm{mg} / \mathrm{mL}$ each). (A) Optical microscopic images of heteroprotein mix solution with or without taurine (20 200 mM). (B) Size of liquid droplets for heteroprotein solution with or without taurine. Experiments were performed in Tris buffer (5mM, pH 7.4). Gray circles indicate the size of each droplet. Mean droplet sizes with SD are indicated by black bars $\left(\mathrm{n}=255^{-347)}\right.$. **; $\mathrm{p}<0.001$ v.s. control. Scale bars $=100 \mu \mathrm{m}$.

Figure 4 LLPS of FITC-labelled lysozyme in lysozyme and ovalbumin mix solution. Optical and fluorescent microscopic images of liquid droplet for FITC-lysozyme and ovalbumin mix solution in Tris buffer (5mM, pH 7.4) with or without taurine. 


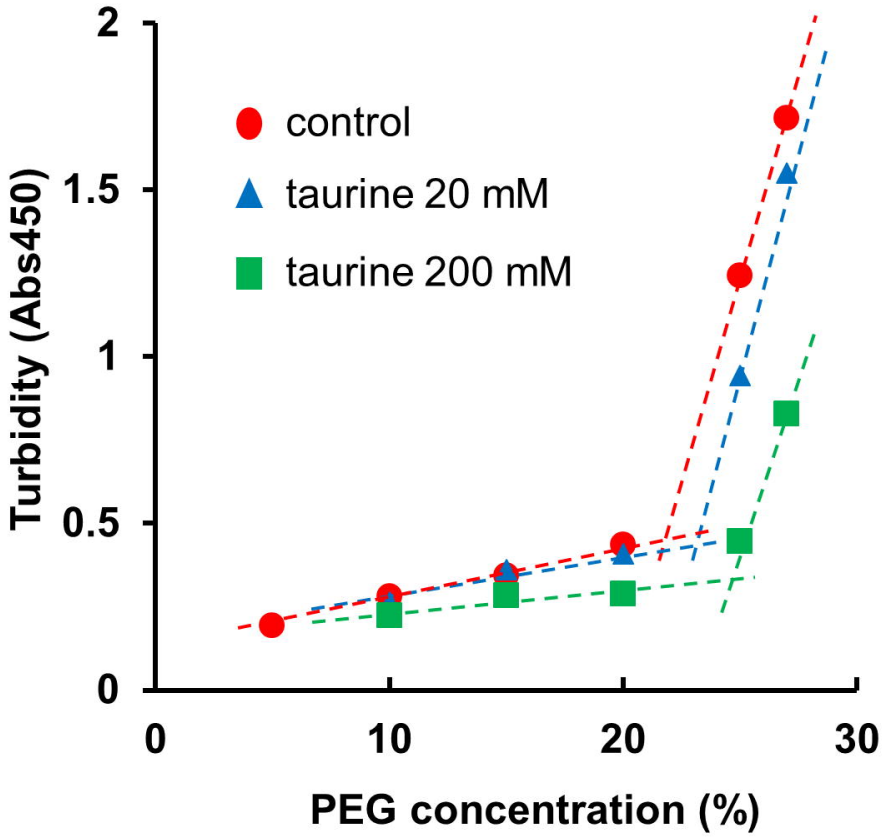


(A)
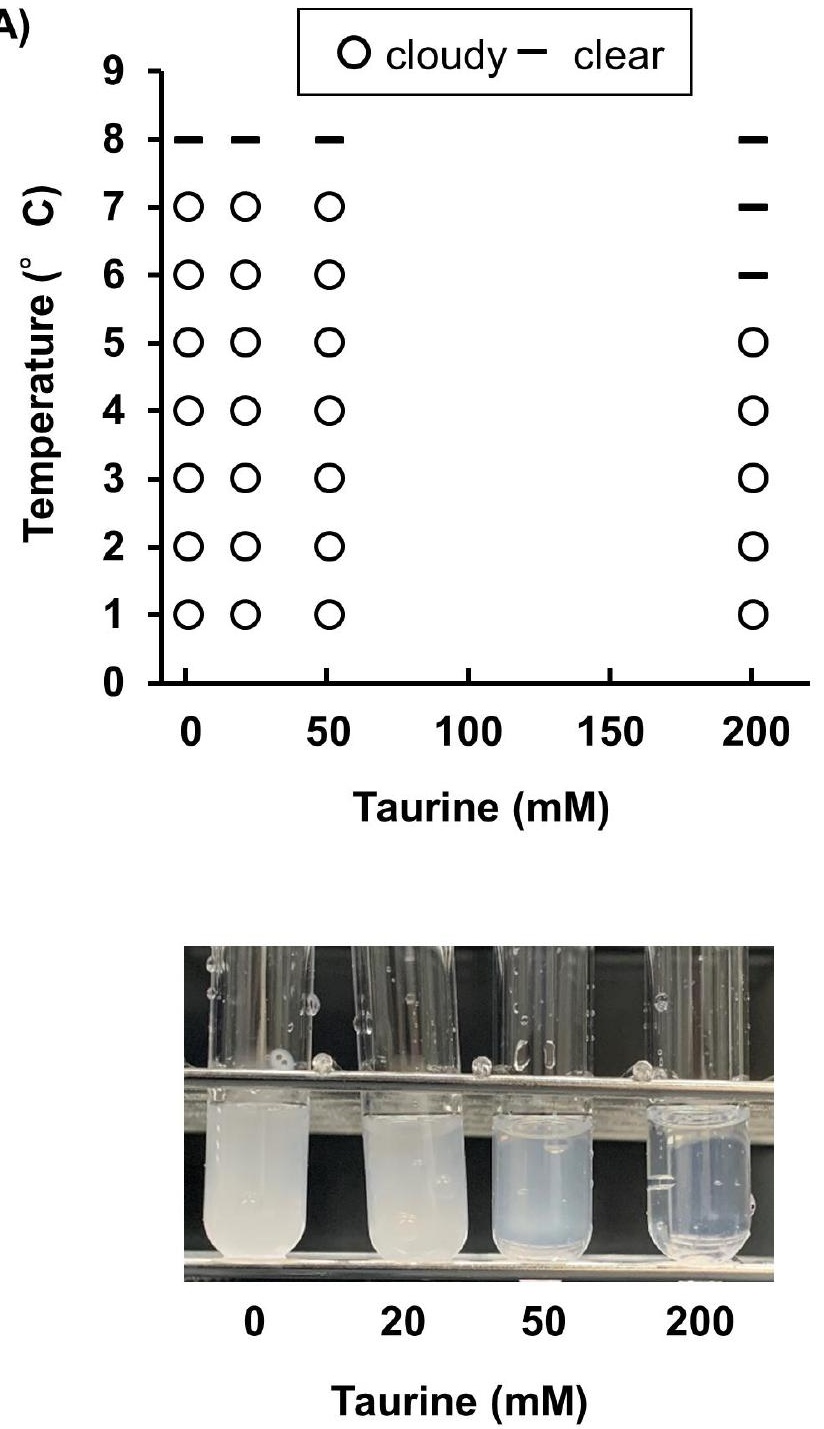

(B)
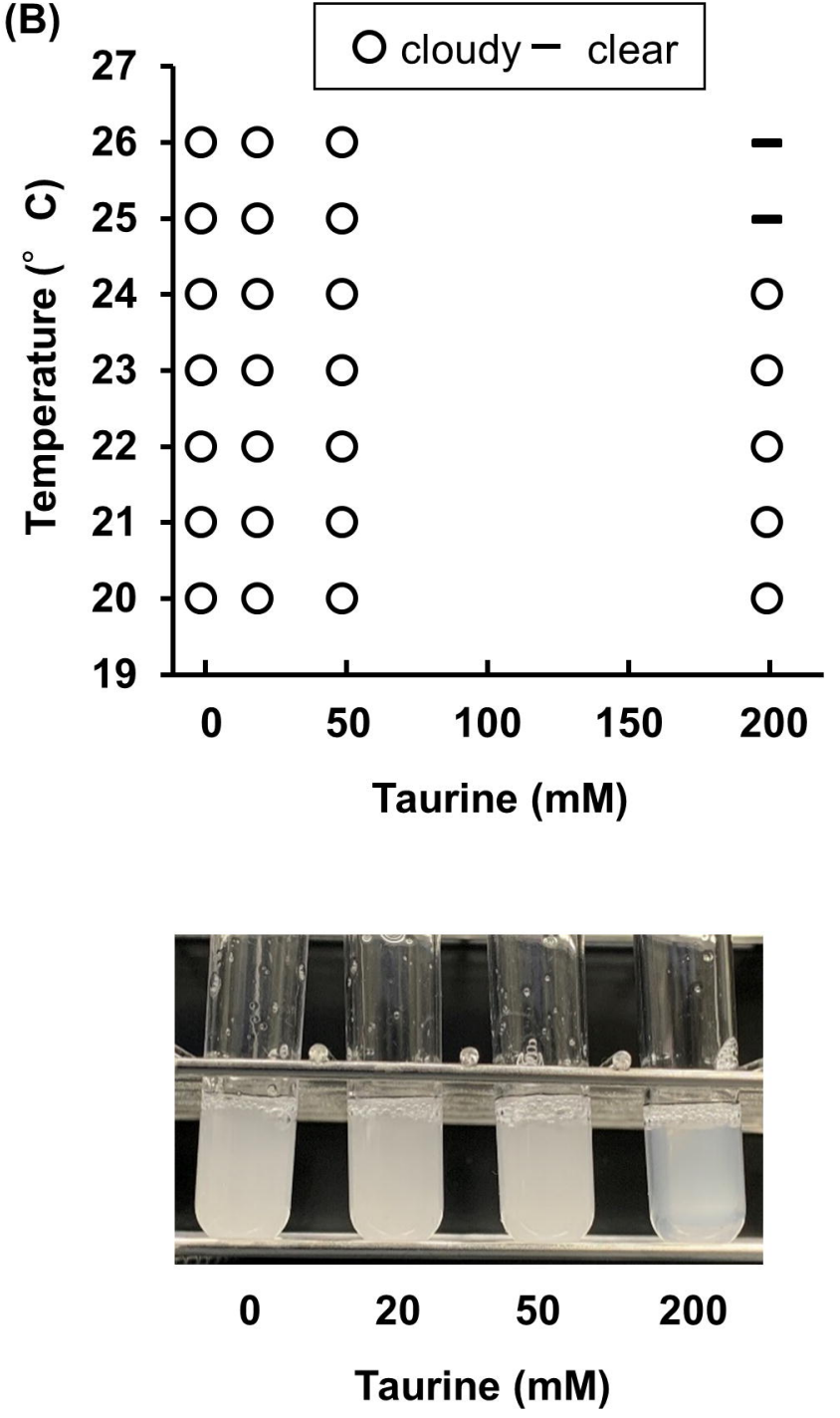
(A)

taurine (mM)
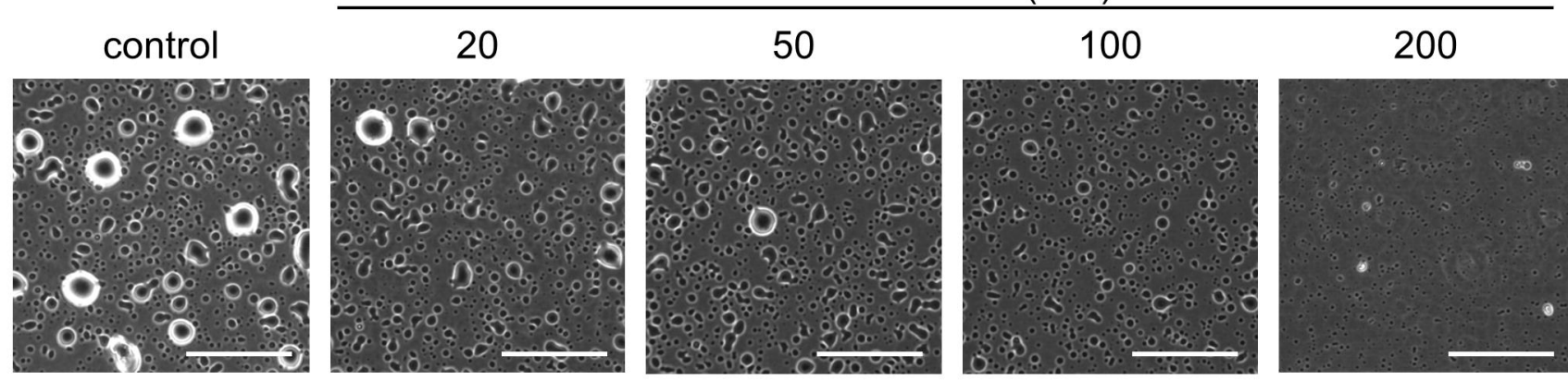

(B)
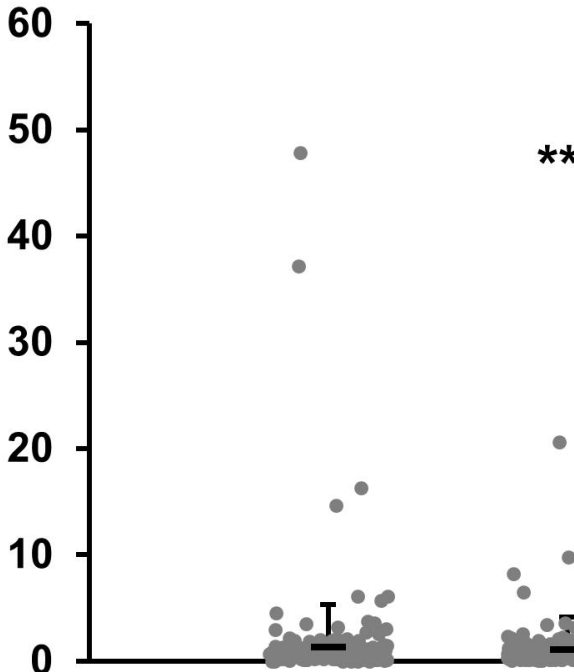

**

-

**

-

**

$* *$

10

0
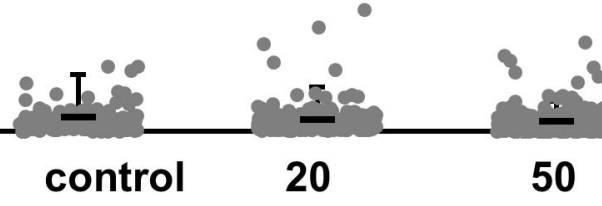

taurine (mM) 
taurine

FITC

Phase Contrast

control
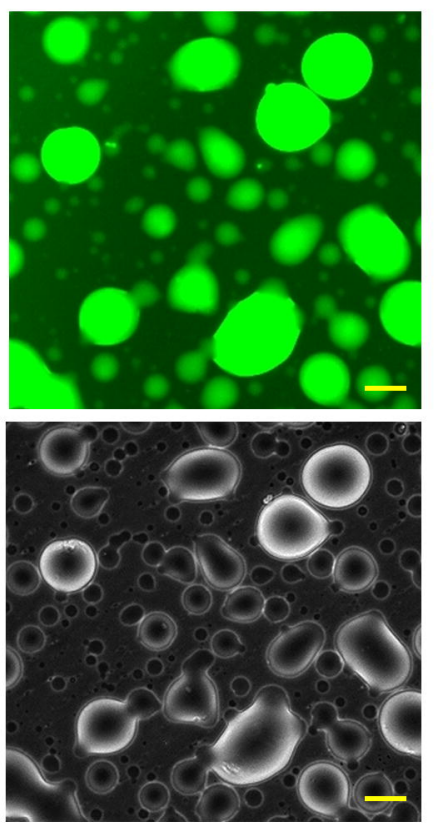

Merge
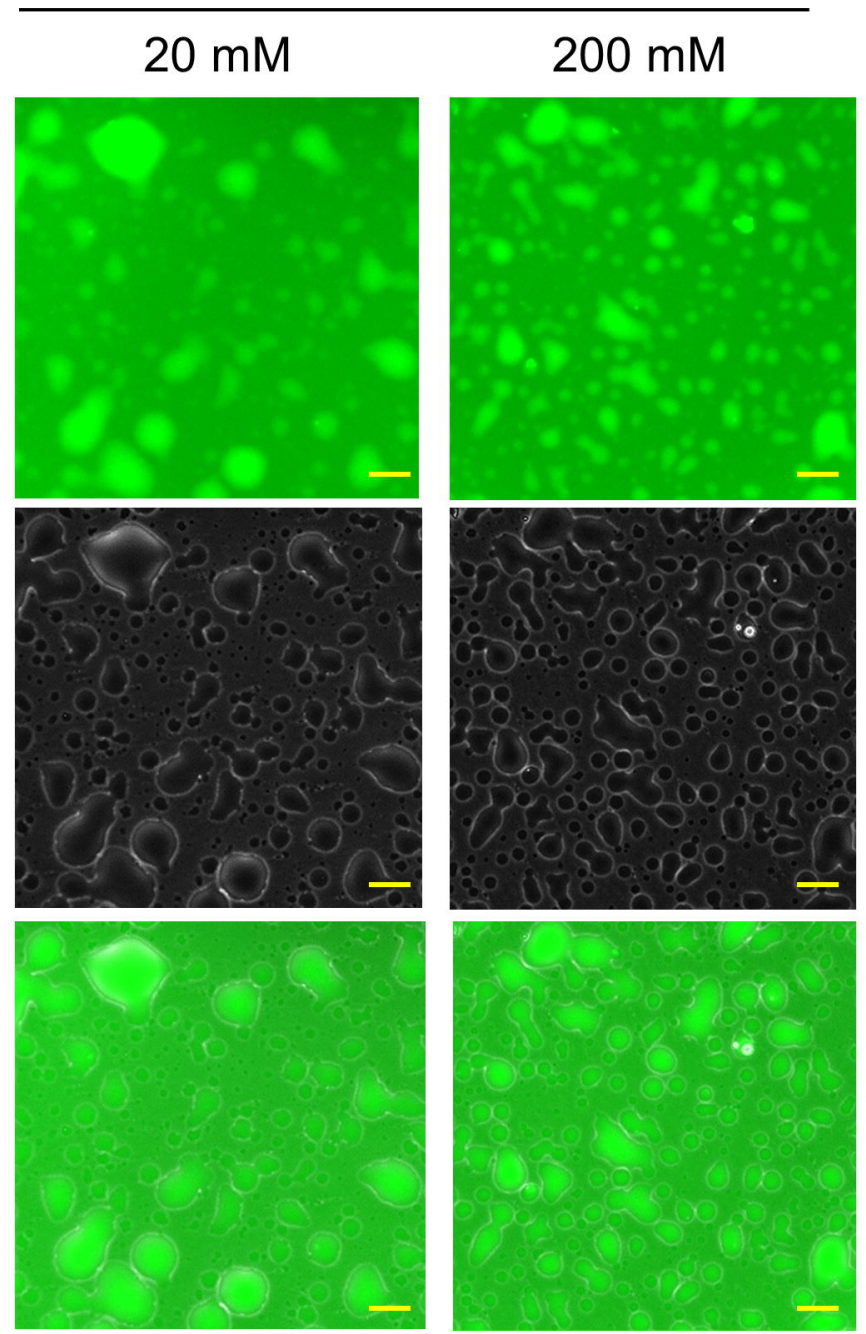